\title{
CARACTERIZAÇÃO POLÍNICA E FÍSICO-QUÍMICA DO MEL DA AROEIRA (Myracrodruon urundeuva Allemão- Anacardiaceae), PRODUZIDO NO ESTADO DO PIAUÍ, BRASIL
}

(Melissopalinological and physical chemical characterization of the honey from Aroeira (Myracrodruon urundeuva Allemão-Anacardiaceae), produced in Piauí, Brazil)

Nubia Dannila Jesus de Oliveira ${ }^{1}$, Juliana do Nascimento Bendini²

${ }^{1}$ Instituto Federal do Piauí - IFPI, Valença do Piauí, Piauí, Brasil; ${ }^{2}$ Universidade Federal do Piauí campus Senador Helvídio Nunes de Barros, Picos, Piauí, Brasil.

*Corresponding author: jbendini@ufpi.edu.br

RESUMO: Este trabalho teve como objetivo caracterizar, por meio das análises polínica e físico-químicas, o mel proveniente da aroeira (Myracrodruon urundeuva Allemão). As amostras (15) foram obtidas, entre os meses de agosto e setembro de 2019, diretamente de apicultores do estado do Piauí e identificadas por número, local e data de colheita, sendo posteriormente submetidas às análises melissopalinológica e físico-químicas (acidez, pH, umidade, açucares redutores, sacarose aparente, cinzas e cor). Como resultados, observou-se que das 15 amostras analisadas, 10 foram identificadas como mel monofloral de aroeira. Vale ressaltar que as amostras apresentaram baixa diversidade de espécies em seu espectro polínico, sendo que em 13,3\% das amostras foi determinado $100 \%$ de predominância do tipo polínico M. urundeuva. Tal informação permite inferir que existe um potencial na região para a produção de mel monofloral da aroeira. O mel da aroeira apresentou as seguintes características físico-químicas: acidez (26,93 meq/kg $\pm 2,85), \mathrm{pH}(3,48 \pm 0,30)$, umidade $(16,4 \% \pm 0,02)$, cor âmbar escuro, açucares redutores $(70,9 \% \pm 1,58)$, cinzas $(0,13 \% \pm 0,4)$, sacarose aparente $(0,93 \% \pm 0,14)$. Os resultados estão de acordo com os limites estabelecidos pela legislação vigente. $O$ mel apresentou características físico-químicas semelhantes à de outros méis monoflorais de aroeira provenientes de regiões semiáridas. Assim, foi possível estabelecer padrões físico-químicos para o mel da aroeira produzido no Piauí, contribuindo para a valorização do mel monofloral do semiárido.

Palavras-chave: apicultura; Caatinga; monofloral.

ABSTRACT: The current paper aims to characterize the honey derived from the aroeira tree (Myracrodruon urundeuva Allemão) through pollen and physicochemical analysis. The samples (15) were obtained directly from beekeepers of the State of Piaui throughout the months of August and September 2019, and then identified by number, 
location and harvest date, subsequently being submitted to melissopalinological and physicochemical analysis (acidity, pH, humidity, reducing sugars, apparent sucrose content, ashes and color). As a result, it was noted that of the 15 samples analyzed, 10 were identified as monofloral honey from the aroeira tree. It's worth noting that the samples presented a low species variety in their pollinic spectrum, and $13,3 \%$ of the samples were determined to be $100 \%$ from the $M$. urundeuva pollinic type. Such information allows the inference of a regional potential for the production of the aroeira tree monofloral honey. The aroeira tree honey presented the following physicochemical characteristics: acidity $(26,93 \mathrm{meq} / \mathrm{kg} \pm 2,85), \mathrm{pH}(3,48 \pm 0,30)$, humidity $(16,4 \% \pm 0,02)$, dark amber color, reducing sugars $(70,9 \% \pm 1,58)$, ashes $(0,13 \% \pm 0,4)$, apparent sucrose content $(0,93 \% \pm 0,14)$. The results are in agreement with the limits established by the current legislation. The honey presented physicochemical characteristics similar to other monofloral aroeira tree honeys originated from semi-arid regions. It was possible, therefore, to establish physicochemical standards for the aroeira tree honey produced in Piauí, contributing to the valorization of the semi-arid's monofloral honey.

Keywords: apiculture; Caatinga; monofloral.

\section{INTRODUÇÃO}

Considerando que o Nordeste brasileiro possui uma rica diversidade de espécies vegetais com alto grau de endemismo (Moro et al., 2014), o mel produzido a partir da flora apícola regional apresenta composição única, com características específicas, principalmente relacionadas ao sabor, perfume e cor (Gois et al., 2013).

Dentre as espécies vegetais ocorrentes no semiárido nordestino, a aroeira Myracrodruon urundeuva Allemão (Anacardiaceae) - se destaca por apresentar enorme resistência e versatilidade (Alves et al., 2019). Segundo Coradin et al. (2018), essa espécie possui excelentes características (secreção de néctar abundante e com alta concentração de açucares) para pastagem apícola.

Bastos et al. (2016) observaram a predominância de grãos de pólen de $M$. urundeuva em amostras de méis coletados na região semiárida de Minas Gerais durante o período seco, indicando, através da análise polínica, que a espécie tem potencial para a produção de mel monofloral nesta região. Essa análise, segundo Tomas et al. (2017), permite atribuir-se a denominação de mel monofloral quando o seu conteúdo polínico provém maioritariamente (pelo menos 45\%) de flores de uma mesma família, gênero ou espécie. Para Bendini e Souza (2008), a caracterização do mel monofloral emerge como parte importante de uma 
estratégia de promoção do produto, conferindo uma identidade e agregando valor ao mel e à apicultura regional.

Entre os Estados nordestinos, o Piauí é o maior produtor de mel e ocupa a $3^{a}$ colocação na produção apícola nacional, tendo excelente aceitação do produto no mercado e uma promissora ascensão, haja vista a sua potencialidade de produção (IBGE, 2018). Pode-se afirmar que a maior parte dos apicultores piauienses e da produção de mel do Estado estão inseridos no Bioma Caatinga, cuja vegetação compreende a ocorrência da aroeira. Segundo Alves et al. (2019), essa espécie arbórea floresce durante os meses secos do ano, entre julho e setembro. Vale ressaltar que a estação seca no semiárido é caracterizada pela menor diversidade de espécies apícolas em florescimento e assim, existe um grande potencial de produção de mel monofloral proveniente da aroeira durante esse período.

Embora Tomas et al. (2017) ressaltem a relevância dos méis monoflorais para o comércio internacional, no Brasil são escassos os estudos de caracterização desse tipo de produto, especialmente no Piauí.

Nesse sentido, o presente estudo teve como objetivo caracterizar, por meio da análise polínica e físico-química o mel proveniente da aroeira no Piauí.

\section{MATERIAL E MÉTODOS}

As amostras foram obtidas por meio do contato com apicultores cooperados da Central de Cooperativas do Semiárido Brasileiro (Casa APIS). Na ocasião, foi solicitado aos produtores que armazenassem as amostras em embalagens devidamente higienizadas e identificadas com o local e data de colheita do mel. Dessa maneira, foram adquiridas 15 amostras durante o período de dezembro de 2018 a janeiro de 2019, provenientes de 13 municípios do Piauí.

As amostras de mel foram encaminhadas ao Laboratório de Pesquisa III da Universidade Federal do Piauí - UFPI campus Senador Helvídio Nunes de Barros (Picos), para a confecção de lâminas e realização da análise melissopalinológica a fim de se identificar a origem botânica do mel. Utilizou-se a coleção polínica (palinoteca) do Grupo de Estudos sobre Abelhas do Semiárido Piauiense (GEASPI/UFPI) como referência para a identificação do pólen de aroeira por meio da comparação.

Dessa maneira, para cada amostra foram preparadas lâminas de mel, em triplicata, a fresco, com gelatina glicerinada pela técnica de Louveaux et al. (1978), conforme o protocolo: $10 \mathrm{~g}$ de mel $10 \mathrm{~mL}$ de água destilada, a solução foi centrifugada a $3000 \mathrm{rpm}$ 
por 10 minutos. O líquido sobrenadante foi descartado e o sedimento de cada tubo de ensaio despejado nas três lâminas, com a lamínula fixada com gelatina glicerinada.

A análise microscópica para a determinação de pólen dominante, acessório e isolado seguiu a classificação de Louveaux et al. (1978): pólen dominante (PD > 45\%), pólen acessório (PA 16\% à 45\%) e pólen isolado (PI 3\% à 15\%). Assim, para a determinação da porcentagem do pólen da Aroeira, em cada lâmina foi realizada uma contagem de um total de quinhentos grãos, onde o percentual era calculado com base na quantidade de grãos de pólen da referida planta encontrados, de acordo com a metodologia proposta por Louveaux et al. (1978).

As análises físico-químicas (acidez total, pH, umidade, cor, açúcares redutores, cinzas e sacarose aparente) foram realizadas no laboratório de análises físico-quimicas da Central de Cooperativas Apícolas do Semiárido Brasileiro - CASA APIS, utilizando a metodologia da Association Of Official Analytical Council - AOAC (1995).

Determinação da Acidez total

A acidez total das amostras de mel foi obtida por meio da determinação da acidez livre e da acidez lactônica. O teor de acidez livre foi obtido pelo método titulométrico que se fundamenta na neutralização por solução de $\mathrm{NaOH} 0,05 \mathrm{~N}$ até a solução atingir um pH de 8,5. Em seguida, aplicou-se a fórmula abaixo descrita:

Acidez livre $=(\mathrm{mL}$ de $\mathrm{NaOH} 0,05 \mathrm{~N}$ utilizados na bureta $-\mathrm{mL}$ branco $) \times 50$

Para o cálculo da acidez lactônica, após a solução alcançar o pH de 8,5 imediatamente pipetaram-se $10 \mathrm{~mL}$ de hidróxido de sódio $0,05 \mathrm{~N}$ e utilizando ácido clorídrico $(\mathrm{HCl})$ 0,05N, fez-se uma titulação de retorno até pH 8,3 com a ajuda de uma bureta.

Acidez lactônica $=(10,00-m L$ de $\mathrm{HCl} 0,05 \mathrm{~N}$ utilizados na bureta) $\times 50$

Acidez total = acidez livre + acidez lactônica

$p H$

Foi determinado segundo o método eletrométrico.

Determinação da umidade

O método utilizado foi o refratométrico, preconizado pela AOAC (item 969.38B) e pela legislação brasileira para controle de qualidade do mel (BRASIL, 2000).

Cor

A cor do mel foi medida tecnicamente em $\mathrm{mm}$ pela escala Pfund (Colorímetro de Pfund).

Archives of Veterinary Science, v.26, n.1, p. 11-24, 2021. 
Determinação quantitativa de açúcares redutores e não redutores (sacarose aparente)

Os açúcares redutores e a sacarose aparente foram quantificados por titulometria utilizando-se reagente de Fehling.

\section{Cinzas}

Para a análise de cinzas das amostras, pesaram-se $10 \mathrm{~g}$ de cada amostra de mel liquefeito e transferiram-se para os cadinhos de porcelana previamente tarados. As amostras foram aquecidas no bico de Bunsen até ficarem carbonizadas. Em seguida, as amostras foram para a mufla à $600^{\circ} \mathrm{C}$ onde permaneceram por 5 horas.

O cálculo foi feito por:

$\%$ de min erais $=\frac{\text { diferença de peso no cadinho }}{\text { peso total da amostra utilizada }}$

\section{RESULTADOS}

Observou-se que das 15 amostras analisadas, 66,7\% foram identificadas como monoflorais de aroeira (Figura 1). Apenas 2 amostras (A14 e A15) não revelaram nenhum pólen de aroeira, 2 amostras apresentaram o tipo polínico referente à aroeira como acessório e apenas 1 amostra como pólen isolado (Tabela 1).
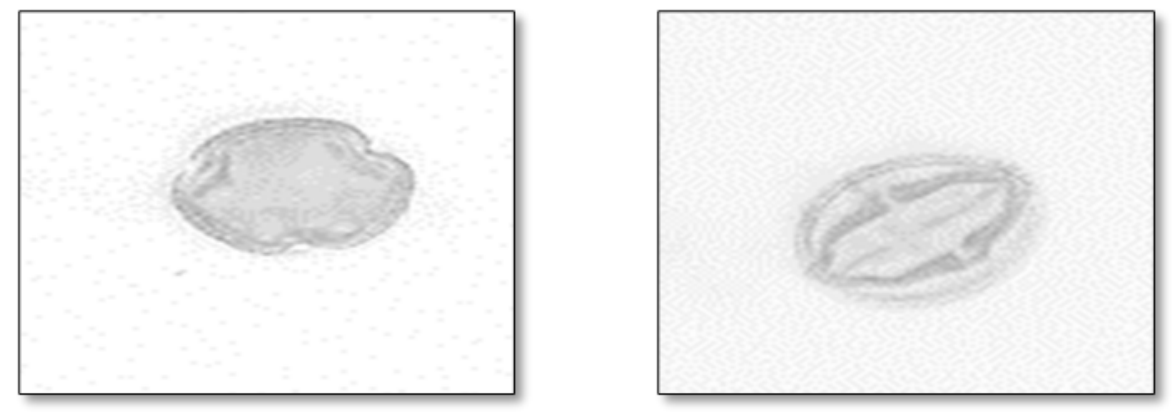

Figura 1 - Pólen de aroeira $M$. urundeuva vista polar e equatorial, respectivamente (400x). Fonte: Registro da autora, 2019.

O pólen da aroeira foi descrito pelas autoras como de tamanho médio, mônade, com simetria radial, isopolar, suboblato, subtriagular, tricolporado, com colpo longo. A ornamentação da exina é reticulada. 
Tabela 1 - Predominância de pólen de aroeira (Miracrodruon urundeuva) nas amostras de mel analisadas.
Amostras
Pólen aroeira
Total pólen
Categoria

(\%)

\begin{tabular}{cccc}
\hline A1 & 58,80 & 51 & PD \\
A2 & 67,32 & 101 & PD \\
A3 & 28,09 & 388 & PA \\
A4 & 100 & 204 & PD \\
A5 & 69 & 78 & PD \\
A6 & 56,39 & 133 & PD \\
A7 & 68,42 & 76 & PD \\
A8 & 3,14 & 191 & PI \\
A9 & 73,33 & 60 & PD \\
A10 & 25,49 & 102 & PA \\
A11 & 65,71 & 105 & PD \\
A12 & 48,09 & 524 & PD \\
A13 & 100 & 1196 & PD \\
A14 & 0,00 & 1266 & - \\
A15 & 0,00 & 2266 & - \\
\hline
\end{tabular}

- Classificação de Louveaux; Maurizio e Vorwohl (1978): pólen dominante (PD > $45 \%$ ), pólen acessório (PA 16\% à 45\%) e pólen isolado (PI 3\% à 15\%).

As amostras de mel estudadas neste trabalho foram consideradas, em sua maioria (66,6\%), monoflorais de aroeira, sendo que destas, 13,3\% não apresentaram nenhum outro tipo polínico em sua composição.

Em relação aos resultados das análises para a caracterização físico-química (Tabela 2), pode-se observar que os parâmetros analisados se apresentaram dentro dos intervalos de variação e limites estabelecidos na legislação brasileira (Brasil, 2000). Na Tabela 2 foi realizada uma comparação com mel monofloral de aroeira M. urundeuva da região do Vale do Rio Jequitinhonha.

Tabela 2 - Resultados das análises físico-químicas do mel da aroeira proveniente do Piauí e do Vale do Rio Jequitinhonha (SANTOS et al., 2018).

\begin{tabular}{cccc}
\hline $\begin{array}{c}\text { Parâmetros físico- } \\
\text { químicos }\end{array}$ & Variação & $\begin{array}{c}\text { Santos } \text { et al. } \\
\text { (2018) mel de } \\
\text { aroeira }\end{array}$ & $\begin{array}{c}\text { Limites } \\
\text { (BRASIL, 2000) }\end{array}$ \\
\hline Acidez Total (Meq/Kg) & 22,73 a 31,44 & 17,32 a 30,64 & $\begin{array}{c}\text { Máximo } 50 \\
\text { meq } / \mathrm{kg}\end{array}$ \\
ph & 3,31 a 4,04 & 3,86 a 4,55 & $3,3-4,6$ \\
Umidade (\%) & $15,2 \%$ a $17,2 \%$ & $16 \%$ & Máximo \\
Cor & Âmbar Escuro & Âmbar escuro & $20 \mathrm{~g} / 100 \mathrm{~g}$ \\
Açucares Redutores & 70,90 & 66,44 & - \\
Cinzas (\%) & $0,02 \%$ a $0,1 \%$, & 0,21 a $0,37 \%$ & $\begin{array}{c}\text { Mínimo } \\
\text { Maximo } / 100 \mathrm{~g}\end{array}$ \\
Sacarose Aparente & $0,93 \%$ & $2,99 \%$ & Maximo \\
& & & $6 \mathrm{~g} / 100 \mathrm{~g}$ \\
\hline
\end{tabular}




\section{DISCUSSÃO}

Ao analisar o mel de aroeira coletado na região semiárida do estado do Piauí, observou-se que $66,66 \%$ das amostras foram consideradas monoflorais. Em relação à frequência de ocorrência de outros tipos polínicos presentes nas amostras, observou-se que somente 1 amostra apresentou até 6 tipos de pólens diferentes. As demais apresentaram de 1 a 4 tipos polínicos, revelando a baixa diversidade de espécies vegetais em florescimento nos locais de coleta das amostras durante a floração da aroeira.

Vale ressaltar que a floração da aroeira ocorre durante os meses de julho e setembro (Alves et al., 2019) e no semiárido sabe-se que esse período é caracterizado pela ocorrência de altas temperaturas, baixa umidade relativa e baixíssimos índices pluviométricos (Melquíades et al., 2020). Santos et al. (2019) ressaltam ainda que o clima influencia na disponibilidade de recursos vegetais às abelhas, já que o período de seca prejudica a floração das espécies apícolas.

Dessa maneira, considerando o período de floração da aroeira, pode-se inferir quanto ao potencial da referida espécie vegetal para a produção de mel monofloral na região semiárida.

O estudo da composição físico-química de méis provenientes de diferentes origens florais é um instrumento para a sua tipificação (Bendini et al., 2010). De acordo com Barth (2004), os méis monoflorais são os mais apreciados, pois são originários de apenas uma espécie de planta, mantendo sempre as características físico-químicas e organolépticas, sendo possível padronizar.

Partindo desse pressuposto, para a apresentação da caracterização físico-química do mel da aroeira, estabeleceu-se um comparativo entre os parâmetros analisados nas amostras provenientes da região semiárida do Piauí e do Vale do Jequitinhonha, Minas Gerais.

Observou-se que o valor médio para acidez foi de 26,93 $\pm 2,85 \mathrm{meq} / \mathrm{kg}$, onde o menor teor foi $22,73 \mathrm{meq} / \mathrm{kg}$ e o maior $31,44 \mathrm{meq} / \mathrm{kg}$. Por meio da acidez é possível avaliar o estado de maturação e de deterioração do mel pois, caso as amostras iniciem algum processo de fermentação, a acidez tende a aumentar (Kadri et al., 2016). No entanto, os valores estão dentro dos parâmetros exigidos pela legislação e próximos dos resultados encontrados por Santos et al. (2018) - 17,32 a 30,64 meq/kg. No entanto, Bastos et al. (2016) encontraram valores de acidez superiores (média de 50,11 meq/kg) para o mel de aroeira produzido na região norte do estado de Minas Gerais. Segundo Gois et al. (2013), vários fatores podem influenciar os valores de pH e acidez do mel, tais 
como: pH do néctar, solo, associação de vegetais para a composição do mel, substâncias mandibulares da abelha acrescidas ao néctar quando transportados até a colmeia e entre outros fatores.

$\mathrm{O} \mathrm{pH}$ das amostras analisadas variou de 3,31 e 4,04 (média 3,48 \pm 0,30). Gois et al. (2013) ressaltam que o pH (potencial hidrogeniônico) e a acidez são considerados importantes fatores antimicrobianos, promovendo maior estabilidade ao produto quanto ao desenvolvimento de microrganismos.

Ainda no que se refere à qualidade do mel, sabe-se que a umidade é um parâmetro importante. Segundo Mota et al. (2018), teores de umidade em torno de 17\% a $18 \%$ dificultam o desenvolvimento de microrganismos, possibilitando o mel a um longo armazenamento sem riscos de fermentação. Além disso, a umidade pode influenciar várias características do mel, como a viscosidade, peso específico, maturidade, sabor e cristalização (Silva et al., 2011).

Para o mel de aroeira proveniente do semiárido piauiense, a média do percentual de umidade das amostras analisadas foi de $16,4 \% \pm 0,02$, com os resultados variando entre $15,2 \%$ e $17,2 \%$. Santos et al. (2018) obtiveram média de $16 \%$ analisando mel do monofloral de aroeira proveniente do Vale do Jequitinhonha. O mel proveniente da florada do cajueiro (Anacardium occidentale L.), espécie nativa, da família Anacardiaceae, foi considerado monofloral de acordo com o estudo de Bendini e Souza (2008). Embora as referidas espécies sejam nativas e pertencentes à mesma família vegetal, as amostras de mel de cajueiro apresentaram média de umidade superior $(18,46 \pm 0,61 \%)$ às médias encontradas para o mel da aroeira, demonstrando que a umidade pode ser influenciada por diversos fatores, desde a origem botânica, condições climáticas e geográficas, além de fatores relacionados à colheita do mel, especialmente se ocorre antes da completa maturação do produto (Silva et al., 2013).

Além da água, o mel é composto por outros componentes, como açucares, aminoácidos, vitaminas e minerais (Crane, 1985).

Os teores médios de açúcares redutores foram de 70,90\% $\pm 1,58$ e para sacarose aparente $0,93 \% \pm 0,24$. O valor médio de sacarose encontrado para o mel de aroeira do Vale do Jequitinhonha foi de 2,99\% (Santos et al., 2018), relativamente mais alto do que o mel do semiárido piauiense, mesmo que ainda dentro do limite estabelecido pela legislação brasileira.

Segundo Sodré et al. (2007), os açúcares redutores (glicose e frutose) representam em torno de 85 a 95\% de carboidratos presentes no mel, os quais têm a capacidade de solubilidade determinando a cristalização (glicose) e a frutose por ter alta 
hidrovascularidade, determina a doçura, sendo que o mel com altas taxas de frutose pode passar anos sem cristalizar.

A quantidade de minerais no mel pode ser identificada por meio do teor de cinzas, resíduos inorgânicos que permanecem após a queima de matéria orgânica de uma amostra de alimento (Gois et al., 2013). Segundo Marchini et al. (2004), os principais minerais identificados no mel são $\mathrm{K}, \mathrm{Na}, \mathrm{Ca}, \mathrm{Mg}, \mathrm{Fe}, \mathrm{Cu}, \mathrm{Zn}$. A quantidade de minerais do mel é influenciada pela origem botânica do néctar que as abelhas coletam, além de fatores relativos ao manejo, ao clima e ao solo da região de origem do produto (Escuredo et al., 2014).

Para o mel de aroeira proveniente do semiárido piauiense, os teores de cinzas variaram de $0,02 \%$ a $0,1 \%$, estando de acordo com as especificações da legislação brasileira. Já o mel de aroeira proveniente do Vale do Jequitinhonha apresentou teores de cinzas que variaram de 0,21 a 0,37\% (Santos et al., 2018). Bastos et al. (2016) encontraram valor médio de $0,28 \%$ de cinzas no mel de aroeira da região norte de Minas Gerais, demonstrando o quanto a quantidade de minerais pode ser influenciada não apenas pela origem botânica, mas por outros fatores, especialmente edafoclimáticos, já que os méis provenientes do semiárido mineiro apresentaram quantidades de minerais mais aproximadas entre si do que das amostras do semiárido piauiense.

A coloração dos méis se apresentou como âmbar escuro em todas as amostras provenientes do semiárido piauiense, bem como nas amostras provenientes do Vale do Jequitinhonha (Santos et al., 2018) e do norte de Minas Gerais (Bastos et al., 2016). Segundo Crane (1985), a cor do mel está relacionada com a sua origem floral, processamento, armazenamento, fatores climáticos durante o fluxo do néctar e a temperatura a qual o mel amadurece na colmeia.

Na comercialização, a cor apresenta-se como o principal critério de escolha do consumidor, uma vez que o consumidor prefere méis com colorações mais claras por terem sabor mais suave que o de méis escuros (Gomes, et al., 2017).

Nesse sentido, a coloração escura faz com que o mel de aroeira seja muitas vezes rejeitado em relação aos méis mais claros. No entanto, descobertas recentes sobre a potencialidade da atividade antibiótica do mel da aroeira (Viana et al., 2018), têm promovido aceitação e valorização do produto e com isso, os apicultores já conseguem comercializar esse mel por um valor $30 \%$ maior que o mel convencional (Lemes e Mendes 2019). 
Além da identificação de propriedades medicinais, Bendini et al. (2010) ressaltam que determinação de um padrão físico-químico para o mel pode consistir em uma estratégia de valorização do produto.

\section{CONCLUSÃO}

A diversidade de espécies vegetais do espectro polínico das amostras de mel de aroeira foi baixa, revelando 0 potencial de produção do mel monofloral proveniente da referida planta na região semiárida do estado do Piauí. O mel de aroeira produzido no Piauí apresentou características físico-químicas semelhantes em relação a outros méis monoflorais de aroeira provenientes de regiões semiáridas. Dessa maneira, os resultados permitiram estabelecer padrões físico-químicos para o mel da aroeira, contribuindo para a valorização do mel monofloral do Piauí.

\section{REFERÊNCIAS}

ALVES, C.A.B.; RIBEIRO, J.E.S.; GUERRA, N.M. et al. Distribuição local e regional de Myracrodruon urundeuva Allemão (Anacardiaceae) no semiárido do nordeste do Brasil.

Revista Brasileira de Geografia Física, v.12, n.3, p.944-960, 2019.

ASSOCIATION OF OFFICIAL ANALYTICAL CHEMISTS - AOAC. Official Methods of Analysis. 16ed. Arlington: AOAC International, 1995. 1025p.

BARTH, O.M. Melissopalinologia no Brasil: uma revisão sobre análises palinológicas de mel, própolis e bolotas de pólen de abelhas. Scientia Agricola, v. 61, n.3, p. 342-350, 2004.

BASTOS, M. A. F.; CALAÇA, P. S. S. T.; SIMEÃO, C. M. G.; CUNHA, M. R. R. Characterization of the honey from Myracrodruon urundeuva (Anacardiceae - Aroeira) in the Dry Forest of northern of Minas Gerais/Brazil. Advances in Agricultural Science, v. 4, n.4, p. 64-71, 2016.

BENDINI, J. N.; SOUZA, D. C. Caracterização físico-química do mel de abelhas proveniente da florada do cajueiro. Ciência Rural, v. 38, n. 2, p. 565-567, 2008.

BENDINI, J. N.; ORSI, R. O.; BENDINI, H. N., SILVA; S.H.M.G. Utilização dos parâmetros físico-químicos e redes neurais artificiais na identificação dos méis de abelhas (Apis 
mellifera L.) produzidos no verão e inverno na microrregião de Campos do Jordão, São Paulo. Boletim da Indústria Animal, v.67, n.2, p.143-149, 2010.

BRASIL, Ministério da Agricultura e do Abastecimento. Instrução Normativa n. 11, de 20 de outubro de 2000. Regulamento Técnico de Identidade e Qualidade do Mel. Diário Oficial da União, Brasília, n. 204, 2000.

CORADIN, L.; CAMILLO, J.; PAREYN, F. G. C. Espécies nativas da flora brasileira de valor econômico atual ou potencial: plantas para o futuro: região Nordeste. Brasília. Série Biodiversidade. DF: MMA, 2018. 262p.

CRANE, E. O livro do mel. São Paulo: Nobel, 1985. 226p.

ESCUREDO, O.; DOBRE, I.; FERNANDEZ-GONZALES, M.; SEIJO, M.C. Contribution of botanical origin and sugar composition of honeys on the crystallization phenomenon. Food Chemistry, v.149, p. 84-90, 2014.

GOIS, G. C.; LIMA, C. A. B.; SILVA, L. T.; RODRIGUES, A.E. Composição do mel de Apis mellifera. requisitos de qualidade. Acta Veterinaria Brasilica. v.7, n.2, p.137-147, 2013.

GOMES, V. V.; DOURADO, G. S.; COSTA, S. C.; LIMA, A. K. O.; SILVA, D. S; BANDEIRA, A. M. P.; VASCONCELOS, A. A.; TAUBE, P. S. Avaliação da Qualidade do Mel Comercializado no Oeste do Pará, Brasil. Revista Virtual de Química, v. 9, n. 2, p. 815-826, 2017.

INSTITUTO BRASILEIRO DE GEOGRAFIA E ESTATÍSTICA - IBGE. Produção Pecuária Municipal. 2018. https://sidra.ibge.gov.br/pesquisa/ppm/quadros/brasil/2018. 23/03/2020.

LEMES, P.G.; MENDES, L.F.C. Mel de Aroeira novidade atrai investidores. Campos \& Negócios, Florestas, v. 7, n.40, 2019.

KADRI, S. M. Identificação de regiões polimórficas para alta produtividade de mel e sequenciamento genômico em abelhas Apis mellifera africanizadas. 2016. Botucatu. 85f. Tese (Doutorado) - Curso de Pós-graduação em Zootecnia, Universidade Estadual Paulista.

LOUVEAUX, J.; MAURIZIO, A.; VORWOHL, G. Methods of melissopalinology. Bee World, v. 59, n. 4, p. 139-157, 1978. 
MARCHINI, L.C.; SODRÉ, G.S.; MORETI, A. C. C. C. Mel brasileiro: composição e normas. Ribeirão Preto: ASP, 2004. 131p.

MELQUÍADES, C.C.V.; BENDINI, J.N.; MOURA, S.G. Internal water supply in Africanized beehives during the dry season in the Brazilian semiarid. Revista Agro@mbiente, v. 14, p. 1-4, 2020.

MORO, M. F., EIMEAR NIC LUGHADHA, E.N., FILER, D.L., ARAÚJO, F.S., MARTINS, F.R. A catalogue of the vascular plants of the Caatinga Phytogeographical Domain: a synthesis of floristic and phytosociological surveys. Phytotaxa, v. 160, n. 1, p. 1-118, 2014.

MOTA, D. D. G; MOURA, G. S; MEDEIROS, S. R. A. Produção de qualidade do mel. Fortaleza: Edições UFC, 2018. 121p.

SANTOS, S.P., CRUZ, G.R.B., SOUSA, D.G., MELO, T.S. Perfil da produção apícola e qualidade físico-química de méis produzidos no agreste paraibano. Archives of Veterinary Science, v.24, n.4, p.24-35, 2019.

SANTOS, E. M. S.; SANTOS, H. O.; GONÇALVES, J. R. S. M. Quali-quantitative characterization of the honey from Myracrodruon urundeuva Allemão (Anacardiceae Aroeira): macroscopic, microscopic, physico-chemical and microbiological parameters. African Journal of Biotechnology, v.17, n.51, p. 1422-1435, 2018.

SILVA, M. B. L.; CHAVES, J. O. B.; VALENTE, M. E. R.; GOMES, J. C.; OLIVEIRA, G. F.; MESSAGE, D. Qualidade de méis produzidos por apicultores e méis provenientes de entrepostos registrados no Serviço de Inspeção Federal. Arquivo Brasileiro de Medicina Veterinária e Zootecnia, v.63, n.4, p.1043-1045, 2011.

SILVA, J.L.A; FARIAS, A.; BOVI, T.S. et al. Caracterização da produção e qualidade físicoquímica de méis produzidos no Estado de Pernambuco. Archives of Veterinary Science, v.18, n.2, p.64-70, 2013.

SODRÉ, G. S.; MARCHINI, L. C.; MORETI, A. C. C. C.; OTSUK, I. P.; CARVALHO, C. A. L. Caracterização físico-química de amostras de méis de Apis mellifera L. (Hymenoptera: Apidae) do Estado do Ceará. Ciência Rural. v. 37, n. 4, p. 1139-1144, 2007.

TOMAS, A., RUSSO-ALMEIDA, P., VILAS-BOAS, M. Avaliação do perfil de açúcares do mel de rosmaninho Português. Revista de Ciências Agrárias, v. 40, número especial, p. 261270, 2017. 
VIANA, F.R., CARMO, L.S., BASTOS, E.M.A.F. Antibacterial activity of Aroeira honeys produced in Minas-Gerais against bacteria of clinical importance. Acta Scientiarum, v. 40, p.e36766, 2018. 